\title{
Halo Nevus
}

National Cancer Institute

\section{Source}

National Cancer Institute. Halo Nevus. NCI Thesaurus. Code C7602.

A benign melanocytic nevus with a halo appearance. 